\title{
Lancet retracts 12-year-old article linking autism to MMR vaccines
}

Published at www.cmaj.ca on Feb. 4

$\mathrm{T}$ welve years after publishing a landmark study that turned tens of thousands of parents around the world against the measles, mumps and rubella (MMR) vaccine because of an implied link between vaccinations and autism, The Lancet has retracted the paper.

In a statement published on Feb. 2, the British medical journal said that it is now clear that "several elements" of a 1998 paper it published by Dr. Andrew Wakefield and his colleagues (Lancet 1998;351[9103]:637-41) "are incorrect, contrary to the findings of an earlier investigation."

Dr. Richard Horton, editor of The Lancet, declined through a spokesperson to speak to $C M A J$ about this issue.

In the original paper, Wakefield and 12 coauthors claimed to have investigated "a consecutive series" of 12 children referred to the Royal Free Hospital and School of Medicine with chronic enterocolitis and regressive developmental disorder. The authors reported that the parents of eight of the 12 children associated their loss of acquired skills, including language, with the MMR vaccination. The authors concluded that "possible environmental triggers" (i.e. the vaccine) were associated with the onset of both the gastrointestinal disease and developmental regression.

In fact, as Britain's General Medical Council ruled in January, the children that Wakefield studied were carefully selected and some of Wakefield's research was funded by lawyers acting for parents who were involved in lawsuits against vaccine manufacturers. The council found Wakefield had acted unethically and had shown "callous disregard" for the children in his study, upon whom invasive tests were performed.

When the original article was picked up by the general media, the findings

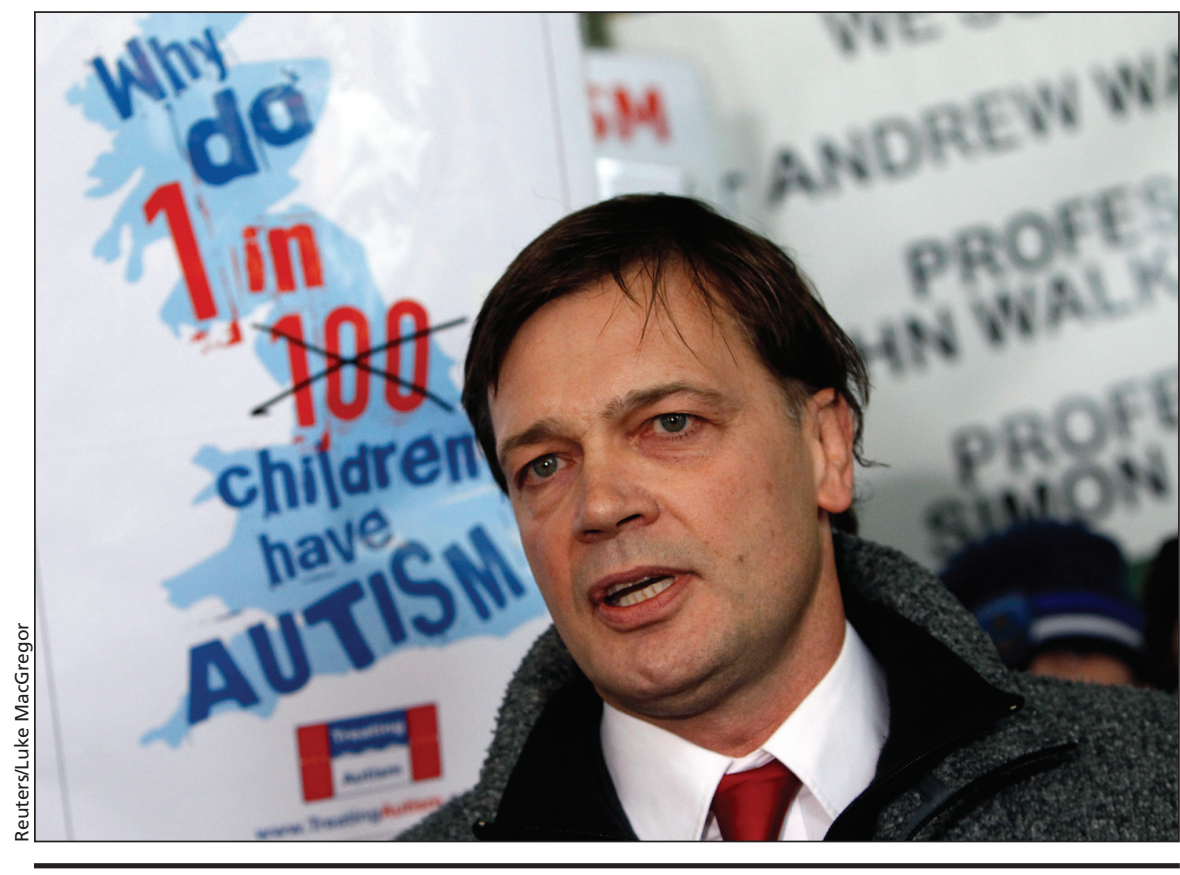

Dr. Andrew Wakefield speaks to media in London, England on Jan. 28 after the General Medical Council ruled that he acted unethically in doing his research into a link between Measles Mumps Rubella vaccinations and autism.

were fuelled by speeches and public appearances in which Wakefield recommended single vaccines rather than the combined MMR. Many parents seeking a cause for their children's illness seized upon the apparent link between the routine vaccination and autism, say Canadian researchers who laud the retraction.

"I think a lot of families were looking for a reason, so they were extremely vulnerable (to this explanation)," says Jeanette Holden, a geneticist at Queen's University in Kingston, Ontario. Holden, whose brother is autistic, heads the Autism Spectrum Disorders Canadian-American Research Consortium.

"The problem is that this had dramatic health consequences, which was that people just didn't vaccinate their children," she adds.

In the United Kingdom, the Health Protection Agency attributed a large measles outbreak in 2008 and 2009 to a concurrent drop in the number of children receiving the MMR vaccine. Pockets of measles - which can be fatal have also cropped up in Canada and the United States as a result of parents' refusal to vaccinate.

"In the course of my discussions with families it's almost invariable that the measles question comes into play," says Dr. Suzanne Lewis, a pediatrician and clinical professor of medical genetics at the University of British Columbia in Vancouver.

"I was quite thankful to see the retraction — it's long overdue," she adds.

Both Holden and Lewis, who is also a member of the Autism Spectrum Disorders - Canadian-American Research Consortium, questioned the article's original heft, given its small sample size.

"Why The Lancet published it is completely beyond me," Lewis says. 
"The risk-versus-benefit equation was really tipped the wrong way by this research that was so egregious."

She also decried the "millions, if not tens of millions of dollars" that have been spent on additional studies to validate or disqualify the original Wakefield study.

The Lancet first investigated the paper in 2004, after allegations of misconduct by Wakefield and the other authors came to its attention. But after an investigation, the Royal Free and University College Medical School and The Royal Free Hampstead NHS Trust published a statement in the journal saying that they were "entirely satisfied" that the children in the Wakefield study "had been subjected to appropriate and rigorous ethical scrutiny" (Lancet 2004.
DOI:10.1016/S0140-6736(04)15711-5).

At that time, The Lancet said its editors found no evidence that the authors intended to deceive them, including about the way the children were selected. However, the editors expressed regret that "aspects of funding for parallel and related work and the existence of ongoing litigation ... were not disclosed to editors." But the journal did not withdraw the paper, citing the "public interest in the issue."

Despite the retraction, many autism advocacy groups and parents continue to defend Wakefield, as they are making clear on blogs such as the Age of Autism, in electronic comments responding to articles about the retraction, and on the website of Generation
Rescue, a group founded by actors Jenny McCarthy and Jim Carrey.

The "conspiracy theory" that vaccine manufacturers are hiding the truth about MMR and autism is fuelled by parents' need to know what is causing autism, says Margaret Spoelstra, executive director of Autism Ontario, despite the fact that no large study has replicated Wakefield's findings.

"We know that autism has a genetic cause and that there are environmental factors that we don't understand yet," Spoelstra says. "There's enormous pressure in the field to come up with those answers." - Laura Eggertson, Ottawa, Ont.

DOI:10.1503/cmaj.109-3179 